DOI 10.37882/2223-2982.2021.12-2.31

\title{
ТРУДНОСТИ ВНЕДРЕНИЯ КОММУНИКАТИВНОГО ПОДХОДА В ОБРАЗОВАТЕЛЬНО-ВОСПИТАТЕЛЬНЫЙ ПРОЦЕСС РКИ В УСЛОВИЯХ ДИСТАНЦИОННОГО ОБУЧЕНИЯ
}

\section{DIFFICULTIES OF INTRODUCING A COMMUNICATIVE APPROACH TO THE EDUCATIONAL PROCESS OF RUSSIAN AS A FOREIGN LANGUAGE IN THE CONDITIONS OF DISTANCE LEARNING}

\section{F. Pafova}

O. Kodzaeva

Summary: The purpose is to study the features of the implementation of the provisions of the communicative approach in the practice of teaching (Russian as a foreign language) in the conditions of distance learning. The scientific novelty lies in the study of problematic aspects that make it difficult to implement a communicative approach in distance learning. The results of the study allow us to identify as such factors: (1) the insufficient level of readiness of teachers to use information and communication technologies in the practice of their professional activities, (2) the insufficiently high level of compliance of didactic materials with communicative learning goals (Russian as a foreign language).

Keywords: communicative approach, Russian as a foreign language, distance learning, communicative goals, information and communication technologies.
$\mathrm{H}$ ачиная с 2020 года, человечество столкнулось с беспрецедентным по своим масштабам и глубине кризисом, вызванным распространением коронавируса и обусловленным им изоляционными мерами. Объявленная пандемия сопровождалась необходимостью сокращения численности контактов людей между собой, что привело к переходу образовательных систем национальных государств, в том числе и России в дистанционный режим. Несмотря на то, что дистанционное образование развивается в РФ не первое десятилетие, большинство педагогов и обучающихся оказались в недостаточной степени подготовлены к реализации деятельности в новых для себя условиях. И педагоги, и обучающиеся столкнулись с целым рядом проблем, вызванных недостаточным уровнем сформированно-
Пафова Фатима Абрековна

К.фрилол.н., дочент, Майкопский государственный технологический университет

Кодзаева Олеся Сергеевна

К.n.н., доцент, Майкопский государственный технологический университет Kodzaeva.olesia@yandex.ru

Аннотация: Цель - изучение особенностей внедрения положений коммуникативного подхода в практику обучения РКИ в условиях дистанционного обучения. Научная новизна заключается в изучении проблемных аспектов, затрудняющих внедрение коммуникативного подхода в условиях дистанционного обучения. Результаты исследования позволяют выделить в качестве таких факторов: (1) недостаточный уровень готовности педагогов к использованию ИКТ в практике своей профессиональной деятельности, (2) недостаточно высокий уровень соответствия дидактических материалов коммуникативным целям обучения РКИ.

Ключевые слова: коммуникативный подход, РКИ, дистанционное обучение, коммуникативные цели, ИКТ.

сти информационной грамотности, отсутствием необходимых дидактических материалов, несоответствием качества разработанных материалов целям языкового обучения в вузе. В целом, полностью изменился образовательно-воспитательный процесс, его фундаментальные основы, базисные концепции, подходы, на которых он строился на протяжении последних десятилетий.

Одним из таких подходов, реализация которого столкнулась с существенными затруднениями, является коммуникативный. В отечественной педагогике подход активно разрабатывался в 70-х годах прошлого столетия, когда главной целью языкового обучения было провозглашено овладение личностью системой изучаемого языка как средства коммуникации, реализации акаде-

Грант Министерства просвещения Российской федерации на реализацию мероприятий, направленных на полноценное функционирование и развитие русского языка, ведомственной целевой программы «Научно-методическое, методическое и кадровое обеспечение обучения русскому языку и языкам народов Российской Федерации» подпрограммы «Совершенствование управления системой образования» государственной программы Российской Федерации «Развитие образования» 
мической, социальной, профессиональной коммуникативной деятельности. С внедрением компетентностного подхода, выступающего средством реформирования национальной образовательной системы, основные положения коммуникативного подхода не только не утратили своей актуальности, но приобрели большую значимость, отражая нацеленность языкового обучения не на накопление системы теоретических знаний о языке, но на формирование коммуникативной компетенции, способности использовать язык как средство общения, интеграции в социум, профессиональное сообщество.

Внедрение основных положений коммуникативного подхода предполагает организацию коммуникативной деятельности, создание условий для общения обучающихся на заданные академические темы, т.е. создание атмосферы «живого» непосредственного взаимодействия в условиях образовательной среды. Разумеется, в условиях дистанционного обучения условия образовательной среды изменились, в ситуации опосредованного взаимодействия между обучающимися и педагогов возникли трудности с организацией коммуникативной деятельности. О проблемах, с которыми столкнулась образовательная национальная система в условиях необходимости перехода на дистанционную форму обучения, написано много, но трудности внедрения положений коммуникативного подхода в практике обучения РКИ в условиях кризиса остаются изученными и осмысленными фрагментарно, готовые «решения», возможные пути преодоления не выработаны. Соответственно, возникает противоречие, обусловленное очевидной значимостью, важностью внедрения коммуникативного подхода в дистанционное языковое обучение, и отсутствием понимания наиболее проблемных аспектов внедрения, а, соответственно, и возможных путей преодоления затруднений с организацией коммуникативной деятельности обучающихся в условиях опосредованного взаимодействия всех участников образовательно-воспитательного процесса. Разрешение указанного противоречия обусловливает актуальность темы исследования.

Целью исследования выступает изучение особенностей внедрения положений коммуникативного подхода в практику обучения РКИ в условиях дистанционного обучения.

Достижение поставленной цели достигалось при помощи следующих методов: метод теоретического анализа (проанализирована отечественная и зарубежная научная литература по проблеме исследования), метод изучения и обобщения педагогического опыта (проанализированы дидактические материалы, которые используются в дистанционном обучения РКИ).

Теоретическую базу исследования составили отече- ственные и зарубежные работы, анализирующие особенности коммуникативного подхода в обучении РКИ (И.А. Зимняя (1985а, 19856, 1991), Э.Г. Азимов, А.Н. Щукин (2009)), изменения образовательно-воспитательного процесса в период пандемии (Rosel, 2020; Shields et al., 2020), трудности, с которыми сталкиваются педагоги в процессе дистанционного обучения (Plowman, Stephen, 2005; Chen, Chang, 2006; Шарипова, 2015; Redecker, 2017), проблемные аспекты разработки дидактических материалов для обучения РКИ (Арутюнов, 1990; Бидайбеков, 2011; Стамболева, 2020).

С учетом заявленной цели, исследование имеет теоретическую направленность, но его выводы могут быть полезны в практическом плане для педагогов, методистов, ученых осуществляющих дистанционное обучение РКИ, разработку программ для обучения русскому языку как иностранному, разработку курсов повышения квалификации педагогов, образовательных программ для педагогических вузов и т.д.

\section{Коммуникативный подход: особенности, сушность}

На начальном этапе работы представляется целесообразным, прежде всего, обратиться к изучению сущности коммуникативного подхода.

Как уже отмечалось, в отечественной педагогике указанный подход разрабатывался в 70-х годах прошлого века, когда он получил свое психологическое обоснование в работах И.А. Зимней (1985а, 19856, 1991). В логике указанного подхода конечной целью языкового обучения было сформулировано формирование коммуникативной компетенции, т.е. «способность осуществлять общение посредством языка» (Азимов, Щукин, 2009, с. 105). В свою очередь, в структуре коммуникативной компетенции (КК) дополнительно выделяют речевую, языковую, социокультурную, компенсаторную, учебнопознавательную и ряд других компетенций (Азимов, Щукин, 2009, с. 105), что позволяет рассматривать КК как сложный, синтезный личностный конструкт, включающий в себя совокупность всех умений и навыков, вовлеченных в процессы речепорождения и интерпретации речи, общения, использования речи в процессе реализации любых форм, видов речевой деятельности. Иными словами, коммуникативный подход носит выраженный практикоориентированный характер, т.е. направлен на формирование практических навыков и умений использования языка как средства коммуникации.

Принимая во внимание выявленную сущность подхода, можно выделить следующие его характеристики, качества (Азимов, Щукин, 2009, с. 105-106):

1. речевая направленность образователно-воспитательного процесса, его нацеленность на обучение 
общению в различных видах речевой деятельности;

2. функциональность в отборе и организации материала. Языковой и речевой материал должен отбираться и вводиться в образовательно-воспитательный процесс в соответствии с интенциями, которые участники коммуникативного взаимодействия стремятся передать при помощи средств языка;

3. ситуативность в процессе организации отработки умений и навыков, т. е. организация в учебной аудитории ситуаций, аналогичных ситуациям реального социального или профессионального общения;

4. использование преимущественно аутентичных материалов, типичных для выражения определенной коммуникативной интенции;

5. использование коммуникативных заданий, направленных на развитие умений общения;

6. индивидуализация процесса обучения, максимально полный учет индивидуального и дифференцированного подходов, особенностей каждого отдельного обучающегося, его уровня владения изучаемым языком, индивидуально-психологических особенностей, потребностей, интересов.

Иными словами, коммуникативный подход направлен на практическое овладение обучающимися изучаемым языком как средством коммуникации, реализации коммуникативной деятельности.

\section{Трудности внедрения коммуникативного по ххо а в условиях Аистаншионного обучения}

Говоря об особенностях внедрения коммуникативного подхода в ситуации дистанционного обучения РКИ, следует отметить, что педагог сталкивается с затруднениями при реализации каждого выявленного выше направления деятельности.

Речевая направленность образовательно-воспитательного процесса, безусловно, сохраняется, целью языкового обучения остается формирование коммуникативной компетенции как средства, инструмента коммуникации, однако в условиях удаленного обучения меняется сама сущность коммуникации, которая протекает опосредовано, при помощи применения современных ИКТ.

В разгар пандемии соседи придумали творческие способы бороться с изоляцией, общаясь с балконов, проявляя творчество, гибкость и высокие способности к адаптации (Rosel, 2020), карантин и самоизоляция привели к более тесным контактам между членами семьи, остановка, снижение интенсивности транспортного движения позволило человечеству лучше слышать пение птиц, смех соседей, их разговоры (Shields et al., 2020, p. 217), однако подобное общение представляется возможным исключительно в ситуации близкого проживания, установление спонтанного, неформального общения не представляется возможным, что оказывает влияние на реализацию социализации, систему неформальных взаимодействий в образовательно-воспитательном процессе.

В целом, зависимость человека от современных информационных технологий, которые часто остаются единственным средством взаимодействия с миром, приводит к тому, что человек полностью погружается в виртуальный мир, существуя в реальности исключительно физически, публичное пространство заменяется цифровой виртуальностью (Shields et al., 2020, p. 219).

Необходимость организации опосредованной коммуникации выдвигает высокие требования к сформированности не только коммуникативной компетенции педагога и обучающихся, но и умений и навыков применения современных технологий в практике собственной деятельности. В целом, необходимость развития цифровой грамотности специалистов разных сфер производственной деятельности сегодня является одной из наиболее важных, актуальных задач, которые стоят перед национальными государствами. На национальном и международном уровнях признается «необходимость вооружить всех граждан необходимыми компетенциями для критического и творческого использования цифровых технологий» (Redecker, 2017, р. 12; Ашилова, Бегалинов, Бегалинова, 2019, с. 42). Национальные государства выдвигают задачу подготовки специалистов, свободно владеющих приемами и методами работы в условиях использования новых информационных технологий (НИТ), подчеркивают, что в ближайшее время навыки владения техникой и технологиями «являются основной компетенцией, необходимой для успеха в формировании карьеры» (Концепция информатизации сферы образования Российской Федерации, 1998; Федулова, 2014, с. 18; Зверева, 2020, с. 16).

Но, несмотря на провозглашение курса на повышение информационной культуры, технологическая подготовка педагогов осуществляется на недостаточном уровне: «большинство исследователей отмечает ухудшение ситуации по этому направлению» (Шарипова, 2015, с. 36). Более того, проблемы с использованием ИКТ формируются уже на этапе школьного обучения, в результате чего уровень квалификации выпускников школы является недостаточным, и учреждениям среднего специального и высшего образования приходится «постоянно осуществлять обучение студентов азам технических наук» (Худяков, 2017, с. 102).

В отдельную проблемную область следует выделить неготовность педагогов к работе с использованием средств информатизации, к использованию современ- 
ных ИКТ (Plowman, Stephen, 2005; Chen, Chang, 2006). Более того, ученые акцентируют внимание на том, что «отсутствие компьютеров, интернета и т.п. - это не проблема на самом деле» (Бидайбеков, 2011, с. 90), т.е. главная проблема заключается не в материальном обеспечении образовательных учреждений, но в неготовности педагогов к использованию ИКТ в практике собственной деятельности.

В качестве причин сдержанного отношения педагогов к использованию технологий исследователи называют наличие негативного опыта обращения к современным технологиям в процессе обучения или отсутствие у педагогов полной информации о возможностях применения цифровых технологий в практике собственной деятельности. Отдельные педагоги «вовсе не хотят с ними знакомиться, не видя в этом большого смысла» (Margaryan, Littlejohn, Vojt, 2011; Jääskelä, Häkkinen, Rasku-Puttonen, 2017; Бурганова, 2019, с. 226). А.А. Строков подчеркивает, что у педагогов «наблюдается весьма настороженная позиция по отношению к инновациям, что порождает дезориентацию, снижение мотивации и недоверие ко всему новому» (Строков, 2020, с. 15). В частности, ряд проведенных эмпирических исследований позволяет сделать вывод о недостаточном уровне готовности педагогов применять ИКТ в практике собственной профессиональной деятельности (Бабина, Шарипова, 2011; Рыжова, Ляш, 2017).

Например, Н.И. Рыжова, А.А. Ляш на основании анализа результатов проведенного эмпирического исследования приходят к выводу, что имеющийся в настоящее время уровень теоретической подготовки учителей «является достаточным лишь в вопросах организации дистанционного обучения и теории цифровых образовательных ресурсов, а уровень практической подготовки можно рассматривать как достаточный лишь в области использования уже готовых образовательных систем и использования ИКТ при разработке ЦОР для обеспечения учебного процесса» (Рыжова, Ляш, 2017, с. 97).

Дополнительно следует подчеркнуть, что трудности с адаптацией к новым технологиям, умениям применять их в практике собственной деятельности представлены у педагогов вне зависимости от их возраста (Бурганова, 2019, с. 225).

И речь идет не о том, что сами педагоги не умеют пользоваться современными технологиями (как правило, большая часть современных специалистов обладают определенными навыками и умениями использования ИКТ), но о неготовности применять их в практике собственной профессиональной деятельности, между тем «очевидно, что от профессионализма преподавателей, владения ими современными знаниями и информационными технологиями в большей части будет зависеть эф- фективность и современность любых систем подготовки педагогов» (Гриншкун, 2011; Гриншкун, 2014, с. 10).

В целом, необходимо отметить, что национальная образовательная система консервативна по своей сути, она в меньшей степени склонна к гибким и оперативным трансформациям, и внедрение технологий не является исключением.

Следует отметить, что низкий уровень готовности педагогов к использованию технологий в практике собственной профессиональной деятельности - проблема, актуальная не только для России, стран постсоветского пространства, но проблема, с которой сталкивается большинство мировых стран. В частности, исследование, проведенное C. Marcelo-García, C. Yot-Domínguez, C. Mayor-Ruiz в Испании, позволяет сделать вывод, что 44,4\% преподавателей испанских вузов редко применяют новейшие технологии в практике своей профессиональной деятельности (Marcelo-García, et al., 2015). Аналогичное исследование, проведенное в Малайзии, выявило, что 78,7\% педагогов являются обычными пользователями современных технологий, но не имеют уровня опытного пользователя (Ghavifekr et al., 2014, p. 30), что еще раз наглядно отображает, что проблема внедрения современных ИКТ в практику педагогической деятельности сегодня остро стоит в большинстве мировых стран, и Россия не является исключением.

В большинстве мировых стран обсуждается проблема психолого-педагогической готовности педагогов к инновационной деятельности, к использованию современных технологий в процессе реализации профессиональных обязанностей. Педагоги сегодня зачастую оказываются в ситуации необходимости применения технологий без соответствующей предварительной подготовки, включаются в инновационные процессы спонтанно, отсутствует учет их профессиональной и личностной готовности к инновационной технологической деятельности. На недостаточном уровне разработано теоретико-методологическое обоснование применения технологий в практике педагогической деятельности, отсутствует высокий уровень скоординированности между существующими методиками, технологиями, основанными на использовании ИКТ, и содержанием государственных программ обучения и воспитания.

Помимо низкого уровня готовности педагогов и обучающихся к организации дистанционного обучения в отдельную проблему выделяется качество информационных ресурсов. Как было выявлено раннее, сущностной характеристикой коммуникативного подхода является функциональность в отборе языкового материала. К сожалению, на сегодняшний день большинство материалов, предназначенных для дистанционного обучения РКИ, характеризуется низким качеством содержатель- 
ного наполнения, несвязностью, несоответствием существующих образовательных ресурсов целям, задачам обучения, требованиям в том числе коммуникативного подхода (Бидайбеков, 2011, с. 90).

Еще в конце прошлого столетия А.Р. Арутюнов в качестве проблемных аспектов обучения РКИ называл отсутствие современных дидактических материалов, подчеркивал, что обучение РКИ характеризуется отрывом между декларируемыми целями и результатами образовательно-воспитательного процесса: внедрение коммуникативного подхода сопровождается формулированием коммуникативных, практических целей, «в то же время учебная литература ориентирована на формирование предкоммуникативных языковых навыков и речевых умений, не соответствующих ни потребностям общества в высококвалифицированных специалистах, ни интересам самих обучающихся» (Арутюнов, 1990, с. 5 - 6; Стамболева, 2020, с. 23). Большинство современных дидактических материалов создавалось в «докоммуникативный» период развития методики обучения РКИ, соответственно, не обеспечивают достижение цели формирования коммуникативной компетенции, которая обеспечит личность возможностями использовать русский язык как инструмент коммуникации, реализации когнитивных процессов и т.д.

Ситуация, к сожалению, мало изменилась и сегодня. 3.А. Стамболева подчеркивает, что в настоящее время ощущается потребность в дидактических материалах по РКИ, которые (Стамболева, 2020, с. 24):

1. учитывают национально-культурные потребности обучающихся;

2. обеспечивают внедрение в образовательно-воспитательный процесс основных положений компетентностного, коммуникативного подходов;

3. ориентированы на развитие коммуникативных умений и навыков обучающихся, «навыков использования русского языка в качестве инструмента реализации когнитивной, академической и профессиональной деятельности, а также как эффективного средства межкультурного общения» (Стамболева, 2020, с. 24).

К сожалению, на сегодняшний день информационные ресурсы и технологии отличаются разрозненностью, отсутствием единства в оформлении, содержательном наполнении, отмечается отсутствие требований и норм, регулирующих особенности разработки и использования информационных ресурсов, в результате чего «подобные средства никак не связаны между собой и неоправданно дублируют одну и ту же информацию, что очень часто приводит к содержательным и методологическим коллизиям» (Бидайбеков, 2011, с. 91). Средства информатизации, которые используются в педагогической практике, должны, с од- ной стороны, тяготеть к универсализации оформления и содержания, с другой - отражать специфику образовательно-воспитательного процесса каждого отдельного образовательного учреждения, лишь при соблюдении этих условий ресурсы могут стать средством оптимизации обучения и воспитания, реализации коммуникативного и компетентностного подходов. Однако на практике, к сожалению, на сегодняшний день информационные ресурсы образовательных учреждений не могут рассматриваться как эффективный инструмент внедрения коммуникативного подхода: «они хаотичны, несвязны, бессистемны, не могут взаимодействовать между собой и в сети, не сопровождаются требуемыми методическими разработками, не удовлетворяют основным психолого-педагогическим, технико-технологическим, дизайн-эргономическим и эстетическим требованиям» (Бидайбеков,2011, с. 97).

\section{ЗакАючение}

Таким образом, подводя итоги исследования, следует отметить, что на сегодняшний день внедрение основных положений коммуникативного подхода в практику дистанционного обучения РКИ существенно затруднено. Анализ теоретических источников позволяет сделать вывод, что основные затруднения обусловлены следующими факторами:

1. недостаточным уровнем готовности педагогов к организации образовательно-воспитательного процесса исключительно при помощи ИКТ. Важно отметить, что речь идет не об умениях использования технологий как таковых, но об интеграции их в профессиональную деятельность. Дополнительно следует подчеркнуть, что указанная проблема свойственна не только для России и стран постсоветского пространства, но, как отражает анализ эмпирических исследований, для многих мировых стран. Кроме того, недостаточный уровень готовности педагогов к внедрению новых технологий в профессиональную деятельность не зависит от возраста, т.е. выпускники педагогических вузов, которые являются активными пользователями интернет-ресурсов, не обладают достаточным уровнем использования этих ресурсов в практике собственной профессиональной деятельности;

2. несоответствие дидактических материалов достижению коммуникативных целей, цели формирования коммуникативной компетенции. На сегодняшний день дидактические материалы, которые применятся в практике дистанционного обучения РКИ, разрабатываются в ситуации отсутствия единства требований, что приводит к отсутствию связи между материалами, частой избыточности информации, ее неоправданному дублированию. 
В сложившейся ситуации очевидной становится необходимость повышения уровня цифровой грамотности педагогов, их готовности к применению современных ИКТ в практике собственной педагогической деятельности. Высокую актуальность приобретает унификация требований к разработке дидактических материалов, предназначенных для обучения РКИ, хотя, безусловно, вариативный компонент должен сохраняться, оставляя место для проявлений педагогического творчества.

\section{Перспективы Аальнейшего исследования}

Разумеется, результаты, полученные в процессе исследования, не исчерпывают все проблемы дистанционного обучения РКИ, работа в данном направлении должна быть продолжена. Прежде всего, приоритетным представляется исследование причин, факторов, которые приводят к недостаточному уровню готовности педагогов применять ИКТ в процессе обучения.

\section{ЛИТЕРАТУРА}

1. Азимов Э.Г., Щукин А.Н. Новый словарь методических терминов и понятий (теория и практика обучения языкам). М.: Издательство ИКАР, 2009.

2. Арутюнов А.Р. Теория и практика создания учебника русского языка для иностранцев. М.: Русский язык, 1990.

3. Ашилова М.С., Бегалинов А.С., Бегалинова К.К. 0 влиянии цифровизации общества на казахстанское образование// Science for Education Today. 2019, том 9, № 6. С. 40 -51.

4. Бабина С.Н., Шарипова Э.Ф. Интегративный подход как условие формирования профессиональных компетенций учителей физики и технологии// Вестник Южно-Уральского государственного гуманитарно-педагогического университета. 2011. № 12.2. С. 7 -14.

5. Бидайбеков Е.Ы. ІТ-подготовка будущих педагогов в Казахстане// Современные информационные технологии и ИТ-образование. 2011. № 7. С. 87 -100.

6. Бурганова Л.А. Социальные риски цифровизации высшего образования// Вестник экономики, права и социологии. 2019, № 4. С. 224 -227.

7. Гриншкун В.В. Информатизация в контексте развития педагогического образования// Вестник Российского университета дружбы народов. Серия: Информатизация образования. 2014. № 2. С. 5 -10.

8. Гриншкун В.В. Особенности подготовки педагогов в области информатизации образования // Информатика и образование. 2011. № 5. С. 68一72.

9. Зверева Е.А. Формирование ИКТ-компетентности бакалавров направления «Приборостроение» в процессе производственной практики: дисс. канд. пед. наук. Чебоксары, 2020.

10. Зимняя И.А. Личностно-деятельностный подход к обучению русскому языку как иностранному // Русский язык за рубежом. 1985. № 5. С. 30 -42.

11. Зимняя И.А. Психологические аспекты обучения говорению на иностранном языке. М., 1985.

12. Зимняя И.А. Психология обучения неродному языку. М., 1989.

13. Концепция информатизации сферы образования Российской Федерации: Спец. вып. М., 1998. Бюлл. 3-4 (13-14).

14. Рыжова Н.И., Ляш А. А. Результаты анализа состояния подготовки будущих учителей информатики в области использования информационно-образовательных систем в профессиональной деятельности// Преподаватель XXI века. 2017. № 1. С. 91 -101.

15. Стамболева 3.А. Формирование лингво-профессиональной компетенции греческих гидов-переводчиков при обучении русскому языку на основе интегрированного подхода (І сертификационный уровень): Дисс. . .. канд. пед. наук.Санкт-Петербург, 2020.

16. Строков А.А. Цифровизация образования: проблемы и перспективы// Вестник Мининского университета. 2020.Т. 8, №2. С. 15.

17. Федулова К.А. Подготовка будущих педагогов профессионального обучения к компьютерному моделированию: дисс. канд. пед. наук. Екатеринбург, 2014.

18. Худяков А.Ю. Технологическая компетентность - одно из важнейших качеств учителя трудового обучения// Актуальные проблемы гуманитар. и естеств. наук. 2017. № 3. С. 101-109.

19. Шарипова Э.Ф. Формирование общетехнологической компетенции будущих учителей технологии. М-во образования и науки РФ, Федеральное гос. бюджетное образовательное учреждение высш. проф. образования «Челябинский гос. пед. ун-т» : монография. - Челябинск : Изд-во ЧГПУ, 2015.

20. Chen J., Chang C. Using computers in early childhood classrooms: Teachers' attitudes, skills and practices// Journal of early childhood research. 2006. № 4 (2). P. 169-188.

21. Ghavifekr S., Razak A.Z.A., Ghani M.F.A., Ran N.Y., Meixi Y., Tengyue Zh. ICT Integration In Education: Incorporation for Teaching \& Learning Improvement// The Malaysian Online Journal of Educational Technology. 2014. Vol. 2, Iss. 2. P. 24 - 45.

22. Jääskelä P., Häkkinen P., Rasku-Puttonen H. Teacher beliefs regarding learning, pedagogy, and the use of technology in higher education // Journal of Research on Technology in Education. 2017. № 49 (3-4). P. 198-211. URL:https://doi.org/10 .1080/15391523.2017.1343691.

23. Marcelo-García C., Yot-Domínguez C., Mayor-Ruiz C. University teaching with digital technologies // Comunicar. 2015. Vol. 23, Issue 45. P. 117-124. D0I: https://doi. org/10.3916/C45-2015-12

24. Margaryan A., Littlejohn A., Vojt G. Are digital natives a myth or reality? University students' use of digital technologies // Computers \& Education. 2011 . № 56 (2). P. 429-440. URL: https://doi. org/10.1016/j.compedu.2010.09.004.

25. Plowman L., Stephen C. Children, play, and computers in pre-school education// British journal of educational technology. 2005. № 36 (2). P. $145-157$.

26. Redecker C. European Framework for the Digital Competence of Educators. - Luxembourg: Publications Office of the European Union, 2017. D0l: https://doi. org/10.2760/159770 
27. Rosel L. Josep Bohigas: El confinament fa que ens replantegem la manera de relacionar-nos amb la família, els veïns i la ciutat//ARA. 2020. URL: https://www.ara. cat/suplements/diumenge/confinament-replantegem-manera-relacionar-nos-familia_0_2425557436.html [Google Scholar]

28. Shields R., Schillmeier M., Lloyd J., Van Loon J. 6 Feet Apart: Spaces and Cultures of Quarantine// Space and Culture. 2020. Vol. 23(3). P. $216-220$.

○ Пафова Фатима Абрековна, Кодзаева Олеся Сергеевна (Kodzaeva.olesia@yandex.ru).

Журнал «Современная наука: актуальные проблемы теории и практики»

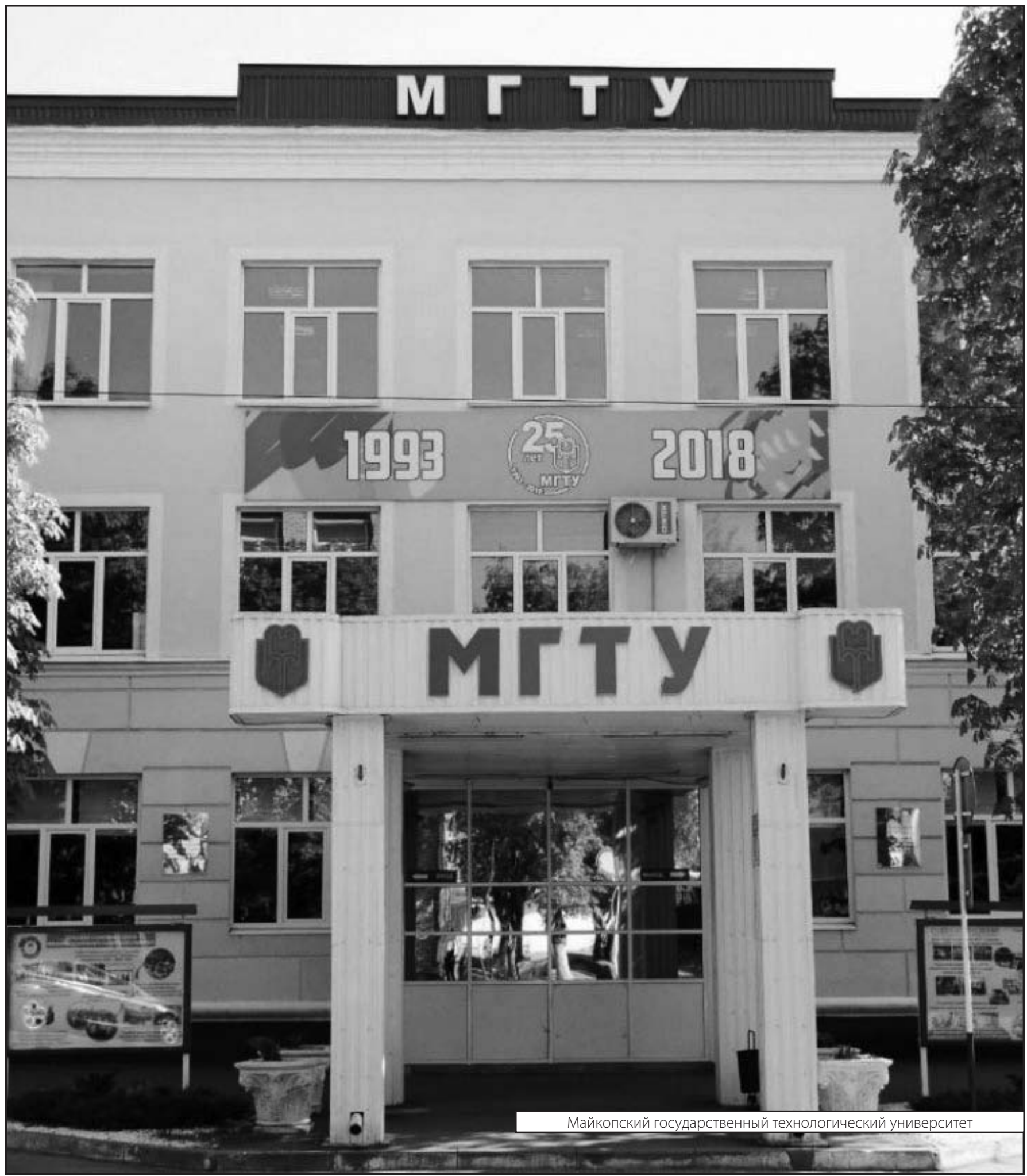

